\title{
Ciberperiodismo audiovisual en España: del modelo televisivo a la construcción de una identidad propia
}

\author{
Ikus-entzunezko ziberkazetaritza Espainian: \\ telebistaren eredutik nortasun propio bat eraikitzera
}

\author{
Audiovisual online journalism in Spain: \\ from the television model to build an identity
}

Javier Mayoral Sánchez ${ }^{1}$

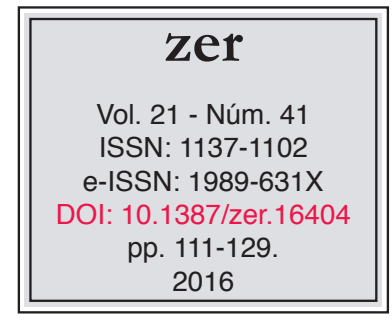

Recibido el 25 de abril de 2016, aceptado el 21 de junio de 2016.

\section{Resumen}

Este trabajo analiza 621 vídeos publicados durante dos semanas en las páginas principales o portadas de cinco cibermedios españoles (abc.es, elconfidencial.com, elmundo.es, elpais.com y lavanguardia.com). Los contenidos, los géneros, los formatos y las estructuras de esos vídeos presentan singularidades notables -tanto en la producción propia como, especialmente, en la externa- respecto a la producción audiovisual típica de los informativos en televisión. Además de los datos del trabajo de campo, este estudio aporta las reflexiones de los responsables de la sección audiovisual acerca de la función de los vídeos en los medios digitales.

Palabras clave: Periodismo digital, cibermedios, periodismo audiovisual, vídeo.

\section{Laburpena}

Lan honek bi astean Espainiako bost ziberkomunikabidetako (abc.es, elconfidencial.com, elmundo.es, elpais.com y lavanguardia.com) orrialde nagusietan edo azaletan agertutako 621 bideo aztertzen ditu. Bideo horien edukiek, generoek, formatuek eta egiturek berezitasun nabariak dituzte -berezko zein, bereziki, kanpoko, ekoizpenean- telebistako albistegietako ohiko ikus-entzunezko ekoizpenen aldean. Landa-lanaren datuez gain, ikerketa honek ikusentzunezkoen arloko arduradunen hausnarketak ere ematen ditu, bideoek komunikabide digitaletan duten funtzioari buruz.

Gako-hitzak: Kazetaritza digitala, zibermedioak, ikus-entzunezko kazetaritza, bideoa.

\footnotetext{
${ }^{1}$ Universidad Complutense de Madrid, javier.mayoral@ucm.es
} 


\begin{abstract}
This paper analyzes 621 videos published during two weeks on the front pages or covers of five Spanish digital newspapers (abc.es, elconfidencial.com, elmundo.es, elpais.com and lavanguardia.com). The contents, genres, formats and structures of these videos have important singularities -both own and external production- in regard to the typical audiovisual production of television news. In addition to data from fieldwork, this study provides the ideas from audiovisual department heads about the role of video in digital media.
\end{abstract}

Keywords: Digital journalism, cybermedia, audiovisual journalism, video. 


\section{Introducción y marco teórico}

El nuevo orden digital ha desencadenado en el periodismo una completa y compleja revolución. Los medios de comunicación han debido afrontar una nueva realidad y adaptarse a un contexto sustancialmente distinto: "el telégrafo alteró la forma de trabajar de los periodistas, pero la dimensión de los cambios introducidos por la digitalización es, probablemente, superior” (Micó y Masip, 2008b: 82). Ese cambio, tan rápido como profundo, ha acabado por afectar a cualquier pieza o fase del proceso comunicativo: desde la organización de las plantillas hasta los principios básicos de elaboración y recepción de los mensajes.

Durante los últimos años se ha destacado la importancia de la personalización y de la actualización permanente de los contenidos periodísticos online, pues internet aporta a la narrativa lineal impresa las nuevas posibilidades técnicas de la informática (Boczkowski, 2004: 21). No obstante, los términos más recurrentes en la descripción del periodismo digital son hipertextualidad, interactividad y multimedialidad. Esos tres rasgos aparecen en la mayoría de los estudios sobre ciberperiodismo (véanse, por ejemplo, Murray, 1999; Nielsen, 2000; Díaz Noci, 2001; Deuze, 2001 y 2004; Manovich, 2005; Salaverría, 2005; Canavilhas, 2007; Masip, 2010).

Conviene aquí centrar la atención en el tercero de los conceptos citados: la multimedialidad. Desde comienzos de siglo han abundado los estudios académicos que abordaban esta cuestión en el marco de investigaciones más amplias sobre la denominada convergencia periodística (Aquino et al., 2002; Deuze, 2004; Micó, Masip y Barbosa, 2009; Masip, 2010). En ese contexto, alguna vez incluso se ha argumentado que la confluencia de medios y códigos supone una posibilidad narrativa (Deuze, 2003), pero no llega a constituir un rasgo definitorio del ciberperiodismo. No se pone en duda que el lenguaje audiovisual en seguida encontró hueco en el soporte digital (Neuberger et al., 1998; Shultz, 1999), pero sí se suele señalar (Masip et al., 2010; Fondevila, 2014) que, en relación con las otras dos características básicas del periodismo online (hipertextualidad e interactividad), la multimedialidad ha sido analizada más tarde y quizá con menor profundidad.

En esa misma línea se han realizado estudios que evalúan el avance tecnológico en los cibermedios. Esa corriente, que arranca ya a finales del siglo XX (Cottle y Asthon, 1999), ha proseguido aportando trabajos durante el último decenio (Boczkowski, 2004; Williams y Franklin, 2007; Thurman y Lupton, 2009; Bock, 2012; Lancaster, 2012). Estos investigadores recurren generalmente al denominado método etnográfico, pues su objetivo es describir cómo se organizan los diferentes modelos de redacción o de empresas periodísticas, qué tareas se les encomiendan a los periodistas, de qué modo les afecta el cambio tecnológico en su desempeño profesional.

Como explican Masip et al. (2010), un segundo grupo de estudios (entre otros, Berry, 1999; Sundar, 2000) se ha centrado, no en la producción, sino en la recepción de los mensajes. Es habitual plantear en este marco el problema de la coordinación de los diferentes códigos empleados. Existe consenso en que no basta con una mera yuxtaposición de los contenidos audiovisuales y textuales (Deuze, 2001; Canavilhas, 2007; Micó y Masip, 2008a), pero plantea muchas más dificultades establecer el 
tipo de conexión o coordinación más eficaz. Algunos autores (Zamarra, 2010) han insistido en la clásica idea de que los sonidos y las imágenes permiten a la audiencia sentir que asiste a los acontecimientos narrados en calidad de testigo, puesto que el relato audiovisual logra mostrar (o sugerir que muestra) una determinada realidad. No obstante, esa sensación no se traduce automática y necesariamente en una mejor comprensión de los hechos (Canavilhas, 2007: 62).

En tercer lugar, se ha investigado la multimedialidad de los cibermedios acudiendo a los clásicos estudios de contenido (véanse, entre otros, Neuberger et al., 1998; Schultz, 1999; Greer y Mensing, 2006; Russial, 2009). El principal objetivo de estos trabajos ha sido medir el grado de implantación de los recursos multimedia en los medios analizados. En la mayoría de los casos se ha intentado establecer, mediante la cuantificación propia del estudio de contenido, hasta qué punto avanzaba el uso de los vídeos en las diferentes cabeceras. Se ha comprobado que los recursos audiovisuales han ido creciendo significativamente con el paso de los años (Greer y Mensing, 2006; Guallar, 2008; Micó y Masip, 2008a; Guallar, Rovira y Ruiz, 2010), si bien se apostilla con frecuencia que las posibilidades de los cibermedios aún son mayores de lo que se constata en los trabajos publicados (Russial, 2009).

Esta tendencia se percibe también en los medios digitales españoles (Marrero, 2008; Masip et al., 2010; Masip, Micó y Meso, 2012; Cassany et al., 2013). En alguna ocasión la metodología cuantitativa ha servido también como punto de partida para realizar consideraciones de carácter cualitativo, por ejemplo en la elaboración de un "ranking de calidad en el uso de la hipertextualidad, multimedia e interactividad" (Fondevila, 2014).

Según se ha visto, el estudio de los vídeos publicados por los cibermedios se ha integrado habitualmente en las investigaciones sobre la multimedialidad. Durante los últimos años se han analizado con especial atención los contenidos multiplataforma (Erdal, 2009) o las singularidades narrativas y técnicas relacionadas con los rasgos distintivos de cada plataforma concreta. Tal perspectiva no impide, sin embargo, considerar cómo es hoy el periodismo audiovisual en los medios digitales. Ese punto de vista permite además relacionar la narrativa del periodismo audiovisual clásico -ligado, como es lógico, a la televisión- con la nueva narrativa de los cibermedios.

En este trabajo se ha preferido analizar la producción audiovisual de medios digitales no especializados precisamente en el vídeo y con una orientación cercana al periodismo tradicional. Los casos de Vice (vice.com/es/), BuzzFeed (buzzfeed. com/?country=es), Vox (vox.com) o Mic (mic.com) pueden resultar ilustrativos de un esfuerzo por innovar en el ámbito audiovisual con propuestas alejadas de los cánones periodísticos.

En cualquier caso, en principio parece muy razonable partir de la idea de que no es ni ha de ser una simple "televisión en la web" (Bradshaw y Rohumaa, 2011: 106), pues el soporte digital impone un tipo de relato con características muy diferentes de las que marcan al periodismo televisual clásico. Las particularidades son tantas que cabe plantear incluso el nacimiento de un nuevo videoperiodismo (Bock, 2012; Lancaster, 2012; Marshall, 2012), que, como es lógico, aún debe afianzar sus señas identidad. 


\section{Objetivos, metodología e hipótesis}

El primer objetivo de este trabajo es cuantificar y analizar los vídeos ${ }^{2}$ publicados en la página principal o portada de cinco cibermedios españoles: abc.es, elconfidencial. com, elmundo.es, elpais.com y lavanguardia.com. Para ello se estudiará la producción audiovisual de esos cinco medios durante dos semanas. En concreto, durante los días comprendidos entre el 2 y el 15 de marzo (ambos incluidos) de 2015, con un registro diario entre las 11:00 horas y las 16:00. Se ha elegido ese periodo para dotar de continuidad temporal a una investigación más amplia que se compone de cuatro trabajos de campo realizados durante un lustro ${ }^{3}$.

Para fijar la muestra han sido determinantes los datos de Comscore, empresa de medición de audiencias que recomiendan tanto la IAB, representante del sector de la publicidad en los medios digitales en España, como la AIMC, Asociación para la Investigación de Medios de Comunicación. Según los índices de audiencia de Comscore, las cinco cabeceras seleccionadas eran las que contaban con mayor número de páginas vistas ${ }^{4}$ en 2012, fecha que se sitúa a mitad de camino de los cuatro trabajos de campo realizados.

Este trabajo recurre a una metodología cuantitativa que se enmarca en el clásico análisis de contenido. El registro sistemático de los vídeos publicados en la portada de los cibermedios seleccionados permitirá conocer el número de piezas audiovisuales difundidas por cada uno de esos cinco medios digitales; los formatos y los géneros periodísticos empleados; los temas o contenidos básicos de los vídeos publicados; y, por último, las estructuras narrativas utilizadas y el grado de implicación de cada medio de comunicación en la elaboración de los materiales audiovisuales que difunde.

Se ha optado aquí por centrar la atención en lo estrictamente audiovisual, dejando para otro tipo de investigaciones todo lo concerniente a la multimedialidad. Por ello no se analiza en profundidad la relación entre las piezas audiovisuales y los textos en los que se integran o a los que acompañan. Sin embargo, eso no quiere decir que se obvie un principio ya difícilmente discutible: el nuevo soporte digital ha generado un tipo de comunicación y una narrativa periodística muy diferente de la que ha establecido durante decenios la televisión clásica. De esa hipótesis, ya manejada en trabajos anteriores (por ejemplo en Cassany et al., 2013), parte este trabajo.

Precisamente para profundizar en esa materia se ha enviado un cuestionario a los cinco responsables de la sección audiovisual de los medios seleccionados.

\footnotetext{
2 Sin excluir otras posibles denominaciones, en este trabajo se prefieren las expresiones "vídeos de cibermedios", "vídeos periodísticos online" o "periodismo audiovisual en internet". El término "vídeo" se emplea en estos contextos en un sentido general que no debe confundirse con un formato concreto (el "vídeo" entendido como VTR).

3 Este estudio forma parte de una investigación cuyo principal objetivo es analizar la evolución entre 2010 y 2015 de la producción audiovisual, de los procedimientos narrativos y de la tipología de vídeos en los cinco cibermedios citados. Mediante azar no probabilista se estableció que los trabajos de campo de 2010 y 2011 se realizarían en noviembre, mientras que los de 2014 y 2015 se harían en marzo.

4 Se prefiere en este trabajo el criterio de "número de páginas vistas" porque introduce precisión respecto al dato -más vago y con frecuencia equívoco- de "usuarios únicos". Sin embargo, conviene admitir la validez metodológica de otras muchas posibilidades (para considerar el grado de fidelización de los lectores, por ejemplo, se podría haber utilizado la "media de visitantes diarios").
} 
Se plantean ahí diez preguntas abiertas (véase el apartado cuarto de este trabajo) relativas a los asuntos centrales previamente abordados. Se recurre, por tanto, a una herramienta metodológica de carácter cualitativo. Dicho cuestionario pretende obtener una explicación acerca de los aspectos esenciales considerados en este estudio. Es verosímil que las respuestas permitan matizar o explicar los resultados alcanzados en el análisis de contenido.

Como segunda hipótesis, cabe sostener que los contenidos audiovisuales tienden a crecer de manera notable en los medios digitales. Este fenómeno no es algo que afecte solo a la ciberprensa. Según un estudio de la empresa Alcatel-Lucent ${ }^{5}$, el tiempo dedicado por cada usuario de internet a ver vídeos se duplicará cada año, hasta 2020. Resulta comprensible que también los cibermedios multipliquen su oferta audiovisual. Esta hipótesis, por lo demás, viene avalada por un buen número de estudios publicados durante los últimos años (Greer y Mensing, 2006; Guallar, 2008; Marrero, 2008; Micó y Masip, 2008a; Guallar, Rovira y Ruiz, 2010; Masip et al., 2010; Masip, Micó y Meso, 2012; Cassany et al., 2013).

La segunda hipótesis de la que se parte en este trabajo puede matizarse del siguiente modo: la producción audiovisual crece en los cibermedios, pero aún de manera irregular, de un modo todavía incipiente. De ahí que convenga estudiar los comportamientos de los cinco medios seleccionados. A propósito de esta tercera hipótesis (y también de la segunda) se acudirá en algún momento a los datos obtenidos en anteriores trabajos de campo, pues esa información permite trazar líneas de evolución muy significativas.

En tercer lugar, se plantea la siguiente hipótesis: la implicación real de los cibermedios en la producción audiovisual no se corresponde con la importancia que en teoría conceden a los vídeos. Para ello, como sugiere algún estudio reciente (OrtellsBadenes, 2016), resultará necesario examinar el tipo de producción (ajena o propia) y el grado de complejidad y elaboración de los vídeos analizados. El cuestionario enviado a los responsables de los medios estudiados también puede resultar útil a este respecto.

\section{Producción audiovisual estable y alejada de patrones televisivos clásicos}

Durante las dos semanas analizadas se han contabilizado 621 piezas audiovisuales en las portadas de los cinco cibermedios seleccionados. En un estudio realizado con idéntica metodología en 2014 se alcanzó una cantidad de vídeos similar (exactamente 618 piezas). Se trata, por tanto, de una producción audiovisual que tiende a estabilizarse tras unos años en los que se ha constatado un aumento considerable de la publicación de vídeos en los medios digitales (véanse, por ejemplo, Guallar, 2008; Guallar, Rovira y Ruiz, 2010; Masip, Micó y Meso, 2012; Mayoral y Edo, 2014). Incluso se ha producido un ligero retroceso respecto al tiempo total dedicado a piezas audiovisuales: los 1.421 minutos registrados en este trabajo de campo se sitúan ligeramente por debajo de los 1.447 minutos computados en el estudio de 2014.

\footnotetext{
5 Véase http://www.inversorlatam.com/366437-Internet-el-consumo-de-video-se-duplicara-cada-ano. note.aspx [consultado el 12 de noviembre de 2013].
} 
Gráfico 1. Vídeos publicados en la portada de los cinco cibermedios.

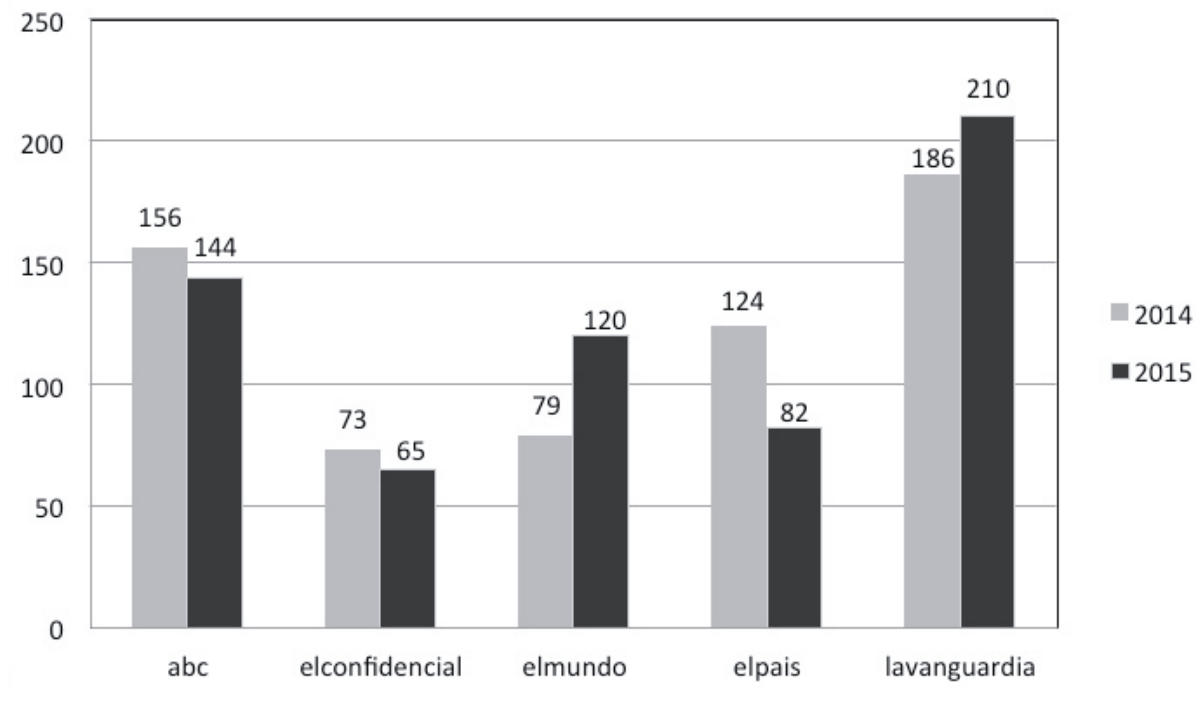

Fuente: Elaboración propia .

La producción audiovisual media es de casi nueve $(8,87)$ vídeos diarios en cada portada, aunque con diferencias muy notables entre las cinco cabeceras estudiadas. Mientras elconfidencial.com ni siquiera llega a las cinco piezas diarias $(4,6)$, la producción audiovisual de lavanguardia.com se sitúa en 15 vídeos cada día. En el centro, ligeramente por debajo de la media del conjunto, se coloca elmundo.es $(8,57$ vídeos diarios).

El Gráfico 1, además de mostrar estas distancias, permite ver cómo ha evolucionado cada uno de los medios considerados respecto al trabajo de campo anterior. Destaca, en primer lugar, la supremacía -incluso reforzada- de lavanguardia.com. Sus 210 piezas suponen el 33,82\% del conjunto de la muestra, más de diez puntos porcentuales por encima de su inmediato perseguidor (abc.es, con un 23,19\% del total de vídeos analizados). Por otro lado, llama la atención la evolución -en cierto modo simétrica- de elmundo.es y elpais.com: la subida del primero es muy similar a la bajada del segundo, de modo que entre ambos se produce una especie de intercambio de posiciones al confrontar los trabajos de campo de 2014 y 2015.

Dos de cada tres vídeos analizados en este trabajo proceden de agencias, productoras u otras entidades. La producción propia (201 vídeos) supone el 32,37\% del conjunto de la muestra. También en este aspecto se aprecian comportamientos muy distintos: elmundo.es llega a un 53,16\% de producción propia, mientras que elconfidencial.com, aun habiendo reforzado su sección audiovisual, solo alcanza a elaborar el 12,33\% de los vídeos que incluye en su portada.

Dentro de la producción ajena, conviene destacar el protagonismo de las agencias de noticias. De las 420 piezas de producción ajena, 173 (el 41,19\%) han sido editadas por agencias. En la gran mayoría de los casos, por EFE y Europa Press. Al margen de consideraciones cuantitativas, la presencia de estos vídeos de agencias es importante porque contribuye a generar un grupo de piezas con identidad 
fácilmente reconocible: por lo general las agencias aportan vídeos breves (de un minuto aproximadamente) con voz en off, totales y estructuras periodísticas tradicionales. Esto significa que los vídeos resultantes se acercan al modelo clásico de los informativos de televisión. Es decir: todo lo contrario de lo que suele ocurrir con el resto de la producción externa, que acostumbra a romper con los patrones estructurales, estilísticos y conceptuales del periodismo televisivo. Con frecuencia en estas piezas de producción ajena incluso cuesta identificar rasgos propios de la narrativa periodística.

Ese conjunto de vídeos no elaborados en agencias ni en el medio que los publica (247, un 39,77\% de la muestra) permitirá explicar un dato muy llamativo que se incluye en la Tabla 1. Obsérvese que la categoría de "Otros" acapara casi un tercio $(32,05 \%)$ de las piezas analizadas. Ese porcentaje sería difícil de entender sin examinar los contenidos habituales de la producción externa pura (descontada la aportación de las agencias de noticias): desde un anuncio de publicidad más o menos curioso hasta un fragmento de un programa de televisión o un vídeo familiar colgado en YouTube. La mayor parte de estos vídeos resulta inclasificable atendiendo a los criterios periodísticos habituales. De ahí que el número de piezas consignado en la categoría de "Otros" doble, por ejemplo, al que aparece en "Nacional" y cuadruplique al de "Internacional".

Tabla 1. Temas de los vídeos analizados.

\begin{tabular}{|c|c|}
\hline Internacional & $\begin{array}{c}48 \\
(7,73 \%)\end{array}$ \\
\hline Nacional & $\begin{array}{c}96 \\
(15,46 \%)\end{array}$ \\
\hline Sociedad & $\begin{array}{c}164 \\
(26,41 \%)\end{array}$ \\
\hline Economía & 21 \\
& $(3,38 \%)$ \\
\hline Cultura & 51 \\
& $(8,21 \%)$ \\
\hline Fútbol & 42 \\
& $(6,76 \%)$ \\
\hline Otros & 199 \\
& $(32,04 \%)$ \\
\hline
\end{tabular}

Fuente: Elaboración propia.

En relación con esta misma tabla, conviene subrayar el protagonismo de los contenidos de "Sociedad" (26,41\% de la muestra). Parece claro que el discurso audiovisual de los cibermedios prefiere centrarse en áreas en las que resulte factible mostrar con imágenes aquello sobre lo que se informa. Los contenidos de "Sociedad" se prestan especialmente a ello. Es mucho más difícil conseguir esa correlación entre imágenes y contenidos en contextos más abstractos en los que 
priman las ideas o los datos ("Economía" o "Nacional", por ejemplo). En estos últimos casos se suele recurrir a declaraciones de protagonistas, en la mayoría de los casos a través de agencias de prensa. La producción propia, en cambio, opta por contenidos que permitan utilizar imágenes con un valor plenamente informativo (y no solo ilustrativo).

De los 51 vídeos incluidos en la categoría de "Cultura", 30 proceden de productoras cinematográficas: en todos estos casos se trata de una pieza promocional (el denominado "tráiler") que avanza o resume el contenido de una película. Otros 12 vídeos son musicales. Así pues, si dejamos a un lado estos formatos de videoclip y tráiler, que suelen llegar a los medios gracias a las distribuidoras musicales o cinematográficas, solo hallamos en la muestra nueve piezas dedicadas a otras manifestaciones culturales.

\section{Géneros, formatos y estructuras}

Los tres conceptos que se incluyen en el título de este apartado prefiguran o anuncian un análisis periodístico de los vídeos que publican los cibermedios seleccionados. Como se comprobará en seguida, los géneros previstos en la Tabla 2 son clásicos: noticia, reportaje, entrevista, crónica y otros géneros de opinión. Lo mismo cabe decir respecto a los formatos. Se acude en este apartado a los que se emplean habitualmente en el periodismo audiovisual (colas, VTR, totales, etc.). Y otro tanto sucede en relación con las estructuras.

Sin embargo, la primera observación que cabe plantear aquí es que una buena parte de los vídeos analizados rompe con los moldes periodísticos tradicionales. Incluso se puede afirmar que una parte sustancial de la muestra ni siquiera presenta rasgo periodístico alguno. Esto, sin duda, resulta sorprendente, pues las cinco portadas estudiadas pertenecen a medios periodísticos -incluso cuatro cabeceras siguen publicando un diario en soporte de papel-. Y, a pesar de ello, muchos de los vídeos que aparecen en sus portadas digitales carecen de valor informativo y escapan a las fórmulas estructurales o expresivas típicas del discurso periodístico. Estas piezas heterodoxas se incluyen en un cibermedio fundamentalmente por su carácter audiovisual. Es decir, por su capacidad para mostrar, gracias a las imágenes, algo que con frecuencia resulta curioso, sorprendente o llamativo, aunque eso que muestra el vídeo en realidad no responda a los criterios periodísticos habituales (novedad, relevancia personal, interés público, etc.) de selección de noticias.

La reflexión anterior puede ayudar a entender por qué casi uno de cada tres vídeos analizados no encaja en ninguno de los géneros periodísticos clásicos. La categoría de "Otros", como se aprecia en la Tabla 2, supera el 30\% de la muestra. Se incluyen ahí, por ejemplo, fragmentos de programas de televisión (36 vídeos que suponen el $5,80 \%$ del total). Puede resultar esclarecedora una descripción muy sucinta del contenido esencial de alguno de estos vídeos: un ovni es supuestamente captado durante la grabación de un documental (material de YouTube que publica lavanguardia.com el 2 de diciembre); un niño de seis años cumple su sueño de pasar un día con los bomberos (vídeo de la cadena $\mathrm{ABC}$ que publica elmundo.es el 4 de diciembre); una presentadora canta en televisión para celebrar que su canal cumple 25 años (elconfidencial.com del 9 de diciembre). 
Tabla 2. Géneros periodísticos empleados en los vídeos.

\begin{tabular}{|c|c|c|c|c|c|}
\hline Noticia & Crónica & Entrevista & Reportaje & Opinión & Otros \\
\hline 292 & 32 & 28 & 70 & 8 & 191 \\
$(47,02 \%)$ & $(5,15 \%)$ & $(4,51 \%)$ & $(11,27 \%)$ & $(1,29)$ & $(30,76 \%)$ \\
\hline
\end{tabular}

Fuente: Elaboración propia.

En cuanto al resto de categorías, destaca el predominio de las noticias. Recordemos el peso de las agencias en la producción audiovisual de los medios seleccionados. El material procedente de agencias (41,19\% de la producción ajena y $27,86 \%$ del total de la muestra) suele reflejar cuestiones de actualidad que, de ordinario, los medios digitales no pueden cubrir por sí mismos. De ahí que las agencias se preocupen por ofrecer noticias. Esto es: relatos informativos de máxima actualidad a través de un lenguaje claro, conciso y no marcado por la subjetividad de quien elabora ese vídeo.

En sentido contrario, la producción propia opta mayoritariamente por géneros alternativos que no excluyen la subjetividad del periodista que elabora las piezas: la crónica $(5,15 \%$ de la muestra), la entrevista $(4,51 \%)$ y sobre todo el reportaje $(11,27 \%)$. Además de ser importante por el aspecto cuantitativo que se acaba de señalar, el género del reportaje en los cibermedios merece ser analizado en profundidad porque ha servido para establecer procedimientos narrativos diferentes a los habituales en televisión (Mayoral y Edo, 2015). Es quizá ahí, en los reportajes de producción propia, donde mejor se puede estudiar el nacimiento de nueva narrativa audiovisual propia de los medios digitales.

El Gráfico 2 muestra que el VTR (video tape recorder) es el formato preferido por los medios online. En este trabajo se han encontrado 257 vídeos con locución grabada. Es decir, el $41,38 \%$ de la muestra analizada. Los totales $(8,86 \%)$ y las colas $(6,92 \%)$ se encuentran a una gran distancia. Resulta evidente, sobre todo en relación con las colas, que las características del soporte digital no son las más adecuadas para estos formatos: solo en los programas en los que participa un presentador pueden combinarse los totales y las imágenes -acompañadas, claro está, de su sonido ambiente- con un texto introductorio de carácter complementario. Eso explica que la fórmula "Colas+Total", muy frecuente en los informativos de televisión, ni siquiera supere en los cibermedios el $1 \%$ de la muestra. De forma más general, esta limitación técnica también explica que, siempre que resulte posible, los cibermedios recurran a un VTR con voz en off o a una combinación de recursos y declaraciones.

El directo, que no aparecía ni siquiera testimonialmente en anteriores trabajos de campo, comienza a emerger como formato útil y eficaz en los medios online. De momento se trata de apariciones muy aisladas: un debate sobre la Unión Europea (11 de marzo) o un acto político del Partido Popular (14 de marzo) en elpais.com, un congreso de tecnología móvil (14 de marzo) en elmundo.es. Sin duda la evolución tecnológica tiene mucho que ver en este cambio que deberá ser analizado con atención durante los próximos años. En cualquier caso, aún existe una distancia enorme con relación al uso del directo en los informativos de televisión. Los tres casos citados suponen tan solo el $0,48 \%$ de la muestra analizada. 
Gráfico 2. Formatos utilizados en los cinco cibermedios.

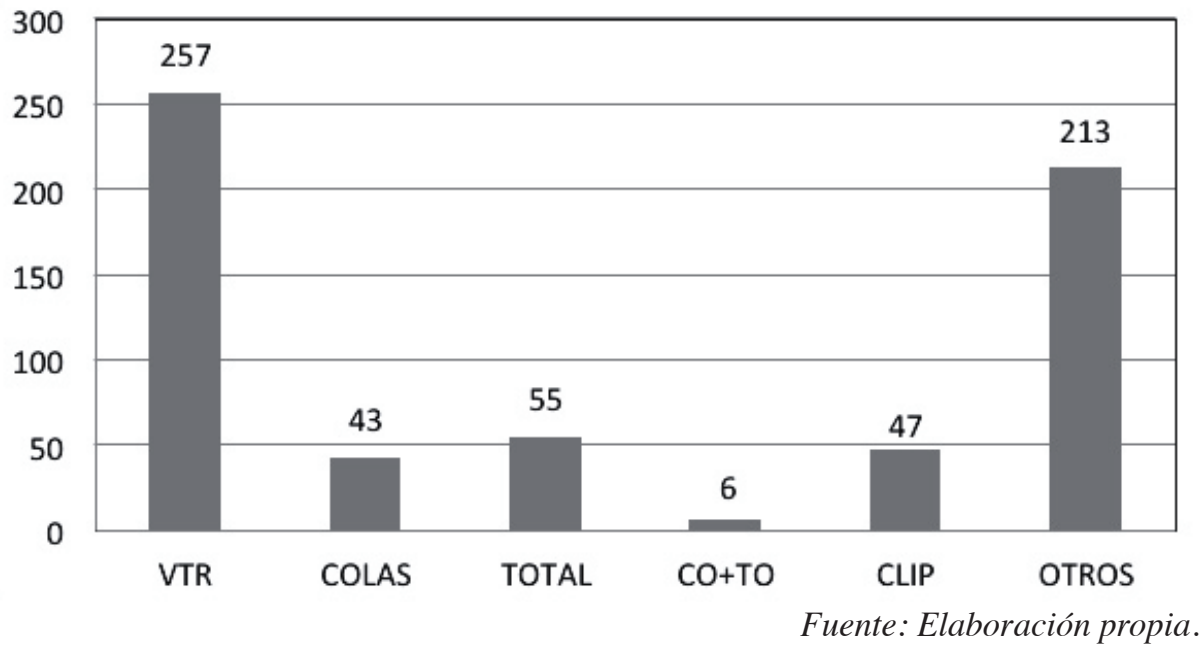

En cuanto a los totales, conviene aclarar que este gráfico registra solo los casos en los que se constata su uso como tal formato. Es decir, como declaraciones aisladas. No se tienen aquí en cuenta, por tanto, los totales que aparecen en el interior de un vídeo que incluye la voz en off de un periodista. En esos casos se considera que la pieza en cuestión recurre al formato VTR. En el conjunto de la muestra se han contabilizado 1081 totales integrados en VTR. Esto supone una media de 1,74 totales por VTR (en el trabajo de campo de 2010 la media se situaba en 1,10 totales por VTR).

Merece la pena, por último, detener de nuevo la mirada en la categoría de "Otros". Las 213 piezas que se consignan en el Gráfico 2 constituyen un grupo muy heterogéneo de vídeos que no resulta posible adscribir a los formatos clásicos de la narrativa audiovisual (Oliva y Sitjà, 1992; Cebrián, 1998; Pérez, 2003; Mayoral y otros, 2008). Se trata de unos vídeos radicalmente inclasificables si se utilizan los criterios periodísticos tradicionales. Forman parte de ese conjunto, por ejemplo, los semibrutos procedentes de agencias: es decir, una especie de premontajes no ideados para su publicación directa, sino más bien para facilitar a los medios de comunicación la tarea de selección de planos.

No obstante, la mayor parte de esas piezas periodísticamente inclasificables son vídeos no profesionales, a menudo sin edición alguna, que han sido compartidos en sitios webs como YouTube. En esta categoría cabe un vídeo familiar, un fragmento de un programa televisivo, un anuncio publicitario o una imagen simplemente curiosa. Los siguientes casos han sido extraídos de la ficha de análisis correspondiente a lavanguardia.com el 13 de marzo: vídeo (30 segundos) en el que el papa Francisco cuenta un chiste sobre argentinos; fragmento de un programa de televisión (23 segundos) en el que Kim Kardashian se desnuda; imágenes grabadas por un ciudadano con su teléfono móvil (36 segundos) tras un accidente de helicóptero.

Cabe plantearse cómo analizar esas piezas conforme a criterios periodísticos clásicos. Desde esa perspectiva sorprende incluso que esos vídeos, aun con clamorosas deficiencias técnicas y formales, terminen siendo publicados por los medios online. 
Y aún resulta más llamativo que el conjunto de estas piezas inclasificables alcance nada menos que al 34,30\% de la muestra analizada.

En consecuencia, no debe extrañar el grado de elaboración de los vídeos publicados que muestra la Tabla 3. En el 51,37\% de las piezas (es decir, la suma de las categorías "In-out" y "Elemental") el proceso de montaje es de una extrema sencillez. No obstante, el denominado "Grado 2", con el que se superan las 15 operaciones de edición, ha aumentado muy significativamente en los últimos años: en el trabajo de campo de 2011, por ejemplo, esta categoría representaba el 17,82\% de la muestra estudiada, mientras que en 2015 llega a un 46,54\% del total. Se deduce de ello, por tanto, que los cibermedios han incrementado de forma muy notable la complejidad interna y el grado de elaboración de los vídeos que publican, aunque más la mitad de esos vídeos resulten todavía muy primarios.

Tabla 3. Tipo de edición ${ }^{6}$.

\begin{tabular}{|c|c|c|c|}
\hline In-out & Elemental & Grado 1 & Grado 2 \\
\hline 243 & 76 & 13 & 289 \\
$(39,13 \%)$ & $(12,24 \%)$ & $(2,09 \%)$ & $(46,54 \%)$ \\
\hline
\end{tabular}

Fuente: Elaboración propia.

Otro síntoma inequívoco de la gran simplicidad técnica de la muestra estudiada es el número de piezas en las que se observa algún tipo de estructura reconocible. La suma de los resultados consignados en la columna derecha de la Tabla 4 (es decir, 302 vídeos) no supera el $49 \%$ del corpus analizado. Esto significa que en más de la mitad de los casos no se ha podido identificar ningún criterio de ordenación interna, ya sea en relación con los contenidos, ya sea respecto a recursos narrativos o elementos formales. Dicho de otro modo: uno de cada dos vídeos se limita a acumular materiales, a yuxtaponer segmentos audiovisuales sin que exista plan narrativo o estructura discursiva.

Las opciones clásicas de la información audiovisual en televisión (Oliva y Sitjà, 1992: 147; Cebrián, 1998: 201; Pérez, 2003: 105-117; Mayoral et al., 2008: 119) son la pirámide invertida, con ordenación por interés decreciente, y la pirámide diseminada, que viene a ser una especie de versión atenuada de la anterior. Esas dos fórmulas acaparan el 37,09\% de los 302 vídeos con estructura reconocible. Entre ambas, se impone con claridad la pirámide diseminada $(27,82 \%)$, pues la pirámide invertida pura ni siquiera llega al 10\%. En comparación con trabajos anteriores, se aprecia un incremento considerable de estas estructuras tradicionales: en 2011, por ejemplo, la

\footnotetext{
${ }^{6}$ Por acciones de edición se entiende el hecho de dar una orden de entrada o de salida, durante el proceso de montaje, a alguno de los planos utilizados en las piezas. Las categorías empleadas en este trabajo son las siguientes: "In-out" (mera reproducción o copia, sin edición alguna del vídeo); "Elemental" (hasta siete operaciones de edición); "Grado 1" (entre siete y 15 acciones de edición); "Grado 2" (más de 15 acciones de edición). En el tipo de edición denominado "Elemental" se ha intentado buscar un grado de complejidad equivalente a unas colas televisuales de 25-30 segundos. Con el llamado "Grado 1" se pretende establecer una categoría que proponga un nivel de complejidad equivalente a un vídeo de 50-60 segundos. El "Grado 2" representa un esfuerzo de edición superior a todos los anteriores.
} 
suma de pirámide invertida y pirámide diseminada representaba el 25,48\% de las piezas con estructura.

Tabla 4. Estructuras empleadas en los vídeos.

\begin{tabular}{|c|c|}
\hline P. Invertida & $\begin{array}{c}28 \\
(9,27 \%)\end{array}$ \\
\hline P. Diseminada & 84 \\
& $(27,82 \%)$ \\
\hline Narrativa & 38 \\
& $(12,58 \%)$ \\
\hline Expositiva & 135 \\
& $(44,70 \%)$ \\
\hline Argumentativa & 9 \\
& $(2,98 \%)$ \\
\hline Cronológica & 6 \\
& $(1,99 \%)$ \\
\hline Otros & 2 \\
& $(0,66 \%)$ \\
\hline
\end{tabular}

Fuente: Elaboración propia.

En cuanto al resto de posibilidades, se observa una nítida prevalencia del orden "expositivo" o secuencial 7 , que roza el $45 \%$ de las piezas estructuradas. Es muy posible que esta fórmula resulte adecuada para organizar el texto en cierta correlación con las imágenes, cuya sintaxis se articula en torno a planos y a secuencias. De ese modo es lógico que surjan los pequeños bloques temáticos que se suelen identificar en esta clase de piezas. En comparación con ese orden secuencial, las estructuras argumentativas $(2,98 \%)$ y cronológicas $(1,99 \%)$ parecen casi marginales.

\section{Estrategias narrativas de los cibermedios}

Se ha considerado oportuno añadir a este estudio algunas reflexiones de los propios cibermedios sobre los vídeos que publican. Para ello se envió un cuestionario con diez preguntas abiertas a los responsables del departamento audiovisual de cada medio analizado. Respondieron cuatro de los cinco jefes de área ${ }^{8}$. El objetivo de ese breve cuestionario es complementar los datos ya expuestos con algunas ideas que

\footnotetext{
7 Se ha denominado así al criterio que establece una sucesión o serie de elementos. Se excluyen aquí el orden estrictamente temporal (que da lugar a una estructura "cronológica") y el utilizado en argumentaciones, juicios, silogismos o, en general, en cualquier tipo de reflexión o especulación. No obstante, sí es cierto que esta "estructura secuencial" puede entenderse como una construcción ligada a la argumental (establece un orden lógico) y a la narrativa (pretende contar algo, sin argumentar ni enjuiciar): primero sucede esto, luego esto otro, luego el tercer punto, etcétera.

8 Carolina Mínguez (abc.es), que será identificada en adelante como "ABC"; Carlos Hernanz (elconfidencial.com), que será llamada "EC"; Enrique Falcón (elmundo.es), "EM"; y Sìlvia Colomé (lavanguadia.com), "LV". No respondió al cuestionario la responsable de elpais.com.
} 
ayuden a entender, entre otras cuestiones, cómo se seleccionan los vídeos y qué géneros, formatos o estructuras se prefieren.

En relación con la selección de contenidos, los cuatro responsables definen ámbitos prioritarios. EM opta por vídeos "de actualidad", ya traten de política, internacional, sociedad o deportes. EC señala "los vídeos de redes sociales (vídeos virales)", vídeos de última hora y piezas de producción propia que refuercen "la línea editorial del medio". ABC y LV coinciden en utilizar el lenguaje audiovisual para aquellos casos en los que "se vea la acción" (ABC). O, dicho de otro modo, "en aquellas informaciones que se comunican mejor con imágenes" (LV). La responsable de este último medio apostilla: "el vídeo muestra y la noticia [escrita] explica".

En general se admite que es conveniente y razonable combinar vídeos de producción propia con los procedentes de agencias u otros agentes. La producción ajena, según LV, es útil especialmente "en el caso de vídeos virales" o "sucesos registrados por usuarios". Respecto a las agencias, "siguen la lógica televisiva, por lo que su impacto en visitas suele estar limitado" (ABC). Su escaso "valor añadido" -apunta EC- obliga a los medios a utilizar estos vídeos de agencia como "complemento informativo", aunque EM considera que al permiten "ahorrar trabajo a los editores". Las piezas de producción propia "responden más a nuestra filosofía informativa y procuramos que el lenguaje audiovisual sea cuidado y apropiado para su consumo online" (LV). ABC destaca que los vídeos propios son colocados en lugares preferentes de la portada. "Siempre, siempre, preferimos vídeos de producción propia", añade EM, pues es una forma de "reivindicar el trabajo de la sección de vídeos".

Es interesante comprobar las dudas de los cuatro medios respecto a la duración ideal de los vídeos: "Seguimos estudiando este tema", responde ABC antes de reconocer que en los primeros 30 segundos se pierde al $50 \%$ de los espectadores. EM distingue entre noticias (que no deben superar el minuto y medio) y entrevistas o reportajes ("intentamos no pasar de tres o cuatro minutos"). EC explica que la duración "en realidad depende del interés del contenido". A diferencia de lo que ocurre en televisión, "no estamos sujetos a la dictadura del tiempo" (LV), por lo que la duración de cada pieza debe ser la necesaria siempre que se mantenga "el ritmo narrativo".

La pregunta sobre la preferencia de géneros periodísticos ofrece también una cierta variedad en las respuestas. ABC entiende que lo ideal es publicar "reportajes y entrevistas". EM opta por "noticias y reportajes". EC asegura que "lo ideal sería [poder publicar siempre] noticias, pero es complicado". LV, como en otras ocasiones, busca una posición de equilibrio: "La noticia siempre será prioritaria, pero procuramos que no falten cada día entrevistas, reportajes y otros géneros periodísticos y de opinión".

Sí hay coincidencia, en cambio, en el formato ideal: VTR con totales y recursos, sin la locución tradicional empleada casi siempre en televisión. ABC, EC y LV marcan directamente esa posibilidad y que, en efecto, este estudio ha localizado mayoritariamente en la producción propia de los cibermedios analizados. EM matiza que la decisión final dependerá del material disponible: hay que "analizar los elementos de los que disponemos (audio, totales, coleos, sonido ambiente, música) antes de realizar el vídeo y decidir de qué manera será más informativo y fácil de ver". La cuestión de la facilidad de uso explica en cierto modo el rechazo a la locución clásica. EC prefiere rotular -sin voz en off- porque, entre otros motivos, "el consumo a 
través de móviles no permite condiciones óptimas de audio". ABC añade argumentos de carácter narrativo: "Es mejor que la historia la cuenten los protagonistas", en la misma línea de LV.

En cuanto a las estructuras de los vídeos, no se descartan las fórmulas tradicionales, sobre todo por su utilidad en las noticias puras: "La pirámide invertida sigue siendo muy útil en el caso de las noticias, y más aún con las breaking news" (LV). Como subraya $\mathrm{ABC}$, se sigue considerando esencial "dar el mejor contenido que tenemos lo antes posible”. No obstante, EC y EM ponen el acento en los elementos de ruptura. Con relación a los modelos tradicionales, según EC, la mayor diferencia "tiene que ver con la cantidad y variedad de recursos narrativos que se pueden incorporar". Aunque los medios siguen utilizando estructuras clásicas -argumenta EM-, "hay muchos nuevos formatos que triunfan entre la gente más joven y que hay que empezar a utilizar".

A propósito de esta última respuesta, surge una reflexión sobre la nueva narrativa digital. EM parte de la premisa que los cibermedios se han equivocado "intentando hacer en la web lo mismo que la televisión". En primer lugar porque los medios digitales no pueden competir en calidad con la televisión de siempre. Sin embargo, con menos calidad puede lograr mayor eficacia. "Bastan unas imágenes relevantes y un texto [un rótulo] que sitúe el hecho informativo", apunta EC. Los vídeos de los medios digitales no deben contar toda la historia, según LV, sino "solo su parte más visual". La historia completa puede aparecer en la pieza textual en la que se integra o a la que acompaña el vídeo. Conviene además pensar en todo tipo de pantallas para "ponerse en la piel del usuario de medios móviles como el smartphone o la tablet" (ABC). Esto origina cambios importantes en la narrativa. Incluso en el tipo de planos utilizados, como indica LV: "tendemos a priorizar los planos cortos en lugar de panorámicas".

\section{Conclusiones}

La primera hipótesis formulada en este trabajo -sugerida ya en el propio título del artículo- conduce a confrontar la narrativa periodística asociada a la televisión con la nueva narrativa audiovisual de los cibermedios. Los datos obtenidos en el trabajo de campo permiten concluir que, en efecto, los vídeos analizados presentan particularidades muy notables en relación con los contenidos, los formatos, los géneros y las estructuras habituales en los informativos de televisión. El cuestionario al que han respondido los periodistas de los medios seleccionados ratifica, al menos en parte, esas singularidades.

En relación con los contenidos, los géneros y los formatos resulta muy significativo el protagonismo de las piezas inclasificables conforme a criterios periodísticos clásicos. De ahí que la categoría de "Otros", en estos tres apartados, adquiera una relevancia tan ostensible: en relación con los contenidos, el 32,05\% de la muestra; en los géneros, el $30,76 \%$; y en cuanto a los formatos, esta categoría de "Otros" acapara nada menos que el 34,30\% de los vídeos hallados. La mayor parte de esos materiales inclasificables procede de páginas web como YouTube. Se trata, por tanto, de piezas no sujetas al modelo de producción propia de los cibermedios ni tampoco a los cánones de las agencias de noticias. No obstante, en las respuestas al cuestionario 
solo uno de los jefes de área consultados cita "los vídeos de redes sociales (vídeos virales)" como tema prioritario para su medio.

Las preferencias de los periodistas, a juzgar por sus respuestas al cuestionario que se les envió, son mucho más previsibles en relación con los géneros, puesto que se citan los tradicionales (noticias, reportajes y entrevistas). Como formato ideal es elegido el VTR, pero sin la locución o voz en off clásica. En cuanto a las estructuras, no descartan la utilidad de las fórmulas tradicionales (pirámide invertida o diseminada), pero enfatizan las diferencias respecto al modelo televisivo e insisten en que los cibermedios no deben contar en sus vídeos "toda la historia, sino solo su parte más visual". El trabajo de campo muestra una clarísima preferencia por las estructuras secuenciales o expositivas (45\% de la muestra), casi diez puntos más que las estructuras tradicionales fundamentadas en un interés decreciente de los argumentos.

La segunda hipótesis, en línea con lo sostenido en trabajos anteriores (Guallar, 2008; Guallar, Rovira y Ruiz, 2010; Masip, Micó y Meso, 2012; Mayoral y Edo, 2014), previó un crecimiento notable de los contenidos audiovisuales en los cibermedios. En el trabajo de campo de 2015 se hallaron 621 vídeos, lo cual supone un aumento de más del $60 \%$ respecto a 2010 (cuando se contabilizaron 388 piezas). No obstante, en el trabajo de campo de 2014 se alcanzó una cantidad de vídeos similar a la de 2015 (exactamente 618 piezas). Puede afirmarse, por tanto, que la producción audiovisual de los medios seleccionados tiende a estabilizarse tras unos años de crecimiento muy significativo.

La producción media de las cinco cabeceras estudiadas es de casi nueve vídeos diarios $(8,87)$. Sin embargo, tal como se anticipaba en la segunda hipótesis de este trabajo, existen notorias diferencias entre los medios analizados: elconfidencial.com no llega a cinco piezas diarias, mientras que lavanguardia.com publica en su portada 15 vídeos cada día. Se trata, en consecuencia, de una producción audiovisual irregular y con amplio margen de crecimiento. El responsable de área de elmundo.es (que coloca en su página principal 8,57 vídeos diarios) asegura en el cuestionario que su objetivo es publicar un vídeo acompañando a cada texto de portada.

Los datos sobre el tipo de producción y el grado de complejidad o elaboración de las piezas analizadas permiten concluir, por último, que la implicación de los cibermedios en la producción audiovisual no se ajusta a la importancia que parecen conceder a los vídeos. Las respuestas de los jefes de área al cuestionario centran la atención en la producción propia, como si esta fuera lo prioritario en la oferta audiovisual de los medios digitales. Sin embargo, esa producción propia (201 vídeos) supone solo el 32,37\% del conjunto de la muestra.

También en relación con lo anticipado en la tercera hipótesis de este estudio, resulta llamativo que en el $51 \%$ de los vídeos registrados haya resultado imposible identificar ningún criterio de ordenación interna (respecto a contenidos, recursos narrativos o elementos formales). Además el 51,37\% de las piezas revela un proceso de montaje muy básico (menos de 15 operaciones de edición). En síntesis, más de la mitad de la producción analizada está formada por vídeos primarios, sin estructura reconocible y con un proceso de edición muy rudimentario. 


\section{Referencias bibliográficas}

AQUINO, R. et al. (2002). The European Multi Media Landscape Report. Heerlen: International Institute of Infonomics.

BERRY, D. L. (1999). Comprehension and recall of internet news: a quantitative study of web page design. Annual Meeting of the Association for Education in Journalism and Mass Communication, 4-7 de agosto de 1999. Recuperado de http://eric.ed.gov/?id=ED434373.

BOCK, May A. (2012). Video Journalism: Beyond the One-Man Band. Nueva York: Peter Lang.

BOCZKOWSKI, P. (2004). Digitizing the News. Innovation in online newspapers. Massachusetts: The MIT Press.

BRADSHAW, P. y Rohumaa, L. (2011). The Online Journalism Handbook. Londres: Pearson Education Limited.

CANAVILHAS, J. (2007). Webnoticias. Propuesta de modelo periodístico para la www. Covilha: Livros Labcom.

CASSANY, R. y otros (2013). El periodismo audiovisual en internet: funciones diferentes, vídeos diferentes. Quaders del CAC, 16(39).

CEBRIÁN, M. (1998). Información televisiva. Mediaciones, contenidos, expresión y programación. Madrid: Editorial Síntesis.

COTTLE, S. y ASHTON, M. (1999). From BBC newsroom to BBC newscentre: on changing technology and journalist practices. Convergence: The journal of research into new media, 3(5).

DEUZE, M. (2001). Online Journalism: Modelling the First Generation of News Media on the World Wide Web. First Monday, 10. Recuperado de http://firstmonday.org/article/view/893/802\#author.

DEUZE, M. (2003). The web and its journalisms: considering the consequences of different types of newsmedia online. New media \& society, 2(5). Recuperado de http://www.multidesign.org/lib/Mark\%2BDeuze\%2B-\%2BThe\%2Bweb\%2Band $\% 2$ Bits\%2Bjournalisms.pdf .

DEUZE, M. (2004). What is Multimedia Journalism? Journalism Studies, 2(5).

DÍAZ NOCI, J. (2001). La escritura digital: hipertexto y construcción del discurso informativo en el periodismo electrónico. Bilbao: Servicio Editorial de la Universidad del País Vasco.

ERDAL, I. J. (2009). Repurposing of content in multi-platform news production. Journalism Practice, 2(3).

FONDEVILA, J. F. (2014). El uso de hipertexto, multimedia e interactividad en periodismo digital: propuesta metodológica y ranking de calidad. Zer, 19(36), 55-76. Recuperado de http://www.ehu.eus/zer/hemeroteca/pdfs/zer36-03-fondevila.pdf.

GREER, J. y MENSING, D. (2006). The evolution of online newspapers: a longitudinal content analysis, 1997-2003. En Li Xigen (ed.): Internet newspapers: the making of a mainstream medium. Lawrence Erlbaum Associates: New Jersey.

GUALLAR, J. (2008). Prensa digital en 2007. En Anuario ThinkEPI, 2008, número 2, Barcelona. 
GUALLAR, J.; ROVIRA, C.; RUIZ, S. (2010). Multimedialidad en la prensa digital. Elementos multimedia y sistemas de recuperación en los principales diarios digitales españoles. El profesional de la información, 6(19).

LANCASTER, K. (2012). Videojournalism on the web. Nueva York: Routledge.

MANOVICH, L. (2005). El lenguaje de los nuevos medios de comunicación. La imagen en la era digital. Barcelona: Paidós.

MARRERO, L. (2008). El reportaje multimedia como género del periodismo digital actual. Acercamiento a sus rasgos formales y de contenido. Revista Latina de Comunicación Social, 63. Recuperado de http://www.revistalatinacs.org/08/29_40_ Cuba/Liliam_Marrero.html.

MARSHALL, S. (2012). BreakingNews launches TV ticker app. En Journalism. co.uk, abril de 2012, Brighton. Recuperado de http://www.journalism.co.uk/ news/breakingnews-samsung-tv-ticker-app/s2/a548825/.

MASIP, P. (2010). El vídeo en los cibermedios: algunas certezas y muchas dudas. En Anuario ThinkEPI, 2020, volumen 4, Barcelona. Recuperado de http://www. thinkepi.net/el-video-en-los-cibermedios-algunas-certezas-y-muchas-dudas.

MASIP, P. et al. (2010). Investigación internacional sobre ciberperiodismo: hipertexto, interactividad, multimedia y convergencia. El profesional de la información, 19(6). Recuperado de http://hdl.handle.net/10171/13561.

MASIP, P.; MICÓ, J. Ll.; MESO, K. (2012). Periodismo multimedia en España. Análisis de los contenidos multimedia en la prensa digital. En III Congreso Internacional de la Asociación Española de Investigación de la Comunicación "Comunicación y riesgo. Tarragona, 18-20 de enero de 2012. Recuperado de http:// Www.aeic2012tarragona.org/comunicacions_cd/ok/100.pdf.

MAYORAL, J. et al. (2008). Redacción periodística en televisión. Madrid: Síntesis.

MAYORAL, J. y EDO, C. (2014). Evolución de la producción audiovisual en cinco cibermedios españoles. Fonseca, Journal of Communication, 9(9), 233-262.

MAYORAL, J. y EDO, C. (2015). Towards a new audiovisual narrative: an analysis of videos published by five online Spanish newspapers. Communication \& Society, 28(1), 145-164.

MICÓ, J. Ll. y MASIP, P. (2008a). Recursos multimedia en los cibermedios españoles. Trípodos, 23.

MICÓ, J. Ll;; MASIP, P. (2008b). Serveis i servituds digitals. Les eines tecnològiques de la vida quotidiana. Vic: Eumo Editorial.

MICÓ, J. Ll.; MASIP, P.; y BARBOSA, S. (2009). Models of business convergence in the information industry: A mapping of cases in Brazil and Spain. Brazilian journalism research, 5 .

MURRAY, J. (1999). Hamlet en la holocubierta. El futuro de la narrativa en el ciberespacio. Barcelona: Paidós.

NEUBERGER, Ch. et al. (1998). Online. The future of newspapers? Germany's dailies on the world wide web. Journal of computer mediated communication, 1(4).

NIELSEN, J. (1999). Designing Web Usability: The practice of simplicity. Indianápolis: New Riders Publishing.

OLIVA, L1. y Sitjà, X. (1992). Las noticias en televisión. Madrid: Instituto Oficial de Radio y Televisión. 
ORTELLS-BADENES, S. (2016). Vídeos de producción propia en la prensa digital: buscando el equilibrio entre la calidad y la inmediatez. Revista Latina de Coтиnicación Social, 71, 1-14.

PÉREZ, G. (2003). Curso básico de periodismo audiovisual. Pamplona: Eunsa.

RUSSIAL, J. (2009). Growth of multimedia not extensive at newspapers. Newspaper research journal, 3(30).

SALAVERRÍA, R. (2005). Redacción periodística en internet. Pamplona: Eunsa.

SUNDAR, S. S. (2000). Multimedia effects on processing and perception of online news: a study of picture, audio and video downloads. Journalism and mass communication quarterly, 3(77).

SHULTZ, T. (1999). Interactive options in online journalism: a content analysis of 100 US newspapers. Journal of computer mediated communication, 1(5).

THURMAN, N. y LUPTON, B. (2008). Convergence calls: Multimedia storytelling at British news websites. Convergence: the international journal of research into new media technologies, 4(14).

WILLIAMS, A. y FRANKLIN, B. (2007). Turning around the tanker: implementing Trinity Mirror's online strategy. Cardiff: Cardiff University.

ZAMARRA, M. M. (2010). El uso del audio y del vídeo en los ciberperiódicos. En M. CEBRIÁN (ed.). Desarrollos del periodismo en internet. Zamora: Comunicación Social. 